\title{
Maturational changes of endothelial vasoactive factors and pulmonary vascular tone at birth
}

\author{
M. Lévy*\#, E. Souil*, S. Sabry*, F. Favatier*, P. Vaugelade ${ }^{+}$, J.C. Mercier", \\ J. Dall'Ava-Santucci*, A.T. Dinh-Xuan*
}

Maturational changes of endothelial vasoactive factors and pulmonary vascular tone at birth. M. Lévy, E. Souil, S. Sabry, F. Favatier, P. Vaugelade, J.C. Mercier, J. Dall'AvaSantucci, A.T. Dinh-Xuan. C ERS Journals Ltd 2000.

ABSTRACT: The aim of this study was to determine which endothelial factors were involved in the decrease of pulmonary vascular resistance at birth, and how they changed with maturation.

Response of intrapulmonary artery rings precontracted with prostaglandin $\mathbf{F}_{2 \alpha}$ were studied from piglets aged $<2 \mathrm{~h}, 2-3$ day, 10 day and adult pigs for pharmacological responses to acetylcholine $(\mathrm{ACh})$ and cromakalim $(\mathrm{CMK})$ in the presence and the absence of the nitric oxide synthase (NOS) inhibitor, $N^{\omega}$-nitro-L-arginine (LNA), the adenosine triphosphate sensitive potassium (KATP) channel blocker, glibenclamide and the endothelin (ET)-A receptor antagonist, BQ123. In situ hybridization and immunochemistry studies were performed in lung tissues of the same animals in order to determine the expression of NOS and ET.

There was a small contractile effect of $\mathrm{ACh}$ in the newborn. Relaxation to $\mathrm{ACh}$, which was blocked by L-NA and reduced by glibenclamide, only appeared from the age of 3 days. The significantly greater relaxation to CMK in rings without endothelium $(\mathbf{p}<0.05)$ was abolished by BQ123 in the newborn, and then disappeared by 2 days of age. Glibenclamide had a greater inhibitory effect on relaxation induced by CMK at 10 days than in the newborn and 2 days old piglets. NOS expression was low in pulmonary arteries of the newborn and increased by 2 days of age whereas the converse was seen with ET expression.

It is concluded that: 1) relaxant response to acetylcholine was absent at birth and appeared at 2 days; 2 ) the reduced relaxant response to cromakalin in rings with endothelium at birth could be blocked by $\mathrm{BQ123}$; and 3) the expression of endothelin decreased whereas the expression of nitric oxide synthase increased from birth to 2 days of age.

Eur Respir J 2000; 15: 158-165.
*Laboratoire de Physiologie Respiratoire, Centre Hospitalier Universitaire Cochin, AP-HP-Université René Descartes, Paris V, France. ${ }^{+}$Institut National de la Recherche Agronomique, 78352 Jouy-en-Josas and Service de Réanimation Pédiatrique, Hôpital Robert Debré, Paris, France. " Service de Chirurgie Cardiaque, Hôpital Laënnec, Paris, France.

Correspondence: A.T. Dinh-Xuan Service de Physiologie-Explorations Fonctionnnelles

Hôpital Cochin

27, rue du faubourg Saint-Jacques

75679 Paris cedex 14

France

Fax: 33144072538

Keywords: Adenosine triphosphatesensitive potassium channel

endothelin

endothelium-derived hyperpolarizing

factor

newborn

nitric oxide

pulmonary artery

Received: December 171998

Accepted after revision September 281999
Pulmonary arterial pressure and resistance are high at birth, and decrease rapidly thereafter due to structural [1-3] and functional $[4,5]$ changes. The underlying mechanisms of these modifications are not fully understood, but nitric oxide (NO) is known to play a role. NO [6-8] is released from the lungs of foetal and newborn animals [5, $9,10]$. It reduces basal tone in utero and contributes to the postnatal fall in pulmonary vascular resistance. However, endothelium-dependent relaxation to various agonists is either absent [11] or very weak [12] until the third day after birth. Then it rapidly increases during the first week of life $[11,12]$. These observations suggest that immediately after birth the interactions between the endothelium and the underlying smooth muscle may be different from those in adult porcine pulmonary vasculature.

Vasodilators such as NO [13], prostacyclin [14], bradykinin [15], endothelium-derived hyperpolarizing factor (EDHF) [16], and vasoconstrictors such as endothelin (ET)-1 [17] and thromboxane [18] are important factors modulating pulmonary vascular tone. ET-1 plasma levels are higher at birth than at 3 days and in adults [19]. Although endothelium-dependent relaxation to acetylcholine (ACh) is absent, the amount of cyclic guanosine monophosphate (cGMP) is high in immature porcine pulmonary arteries [20]. Endothelium-dependent relaxation to ACh is inhibited by antagonists of the muscarinic M1 and M3 receptor subtypes at 3 days of age, whereas it is inhibited only by the M3 blockers in adult porcine pulmonary artery [20]. EDHF and NO release is induced by activation of the M1 and M3 subtypes, repectively [21]. These observations suggest that ACh mainly acts via the NO pathway in adults, whereas both NO and EDHF pathways are likely to be involved in the immature vessels. EDHF hyperpolarizes vascular smooth muscle cells through activation of adenosine triphosphate sensitive potassium (KATP) channels [5, 9, 12].

To further investigate the role of pulmonary vascular endothelial cells in the control of newborn pulmonary vascular tone, this study tested the relaxant response to $\mathrm{ACh}$ and cromakalim (CMK), a KATP channel opener, in 
the presence and absence of NO synthase (NOS) inhibitors, KATP channel blockers, and ET-A receptor antagonists, in isolated porcine pulmonary artery vessels taken from newborn $(<2 \mathrm{~h}), 2-3$ days old and 10 day old animals and from adult animals. Furthermore, protein expression of endothelial constitutive NOS3 and ET-1 and expression of messenger ribonucleic acid (mRNA) encoding for NOS3 were also examined in the lungs of differently aged animals ( 2 h, 2-3 days, 10 days). The response of pulmonary artery rings to the ET-B receptor agonist, sarafotoxin 6c (SF6c), was also tested.

\section{Methods}

The isolated intrapulmonary arteries of three large adult white pigs and 20 piglets aged $<2 \mathrm{~h}(\mathrm{n}=7), 2-3$ days $(\mathrm{n}=8)$, and 10 days $(n=5)$ were studied. The piglets were taken from 13 sows. Animals received human care compliant with the "Principles of Laboratory Animal Care" [22] and the "Guide for the Care and Use of Laboratory Animals" [22]. The piglets were delivered normally and killed by exsanguination after being anaesthetized with inhaled isoflurane or halothane. The heart and lungs were removed en bloc and placed in cold Krebs-Ringer bicarbonate solution of the following composition (in $\mathrm{mM}$ ): $\mathrm{NaCl} 118, \mathrm{KCl} 5.9, \mathrm{CaCl}_{2}$ 2.5, $\mathrm{MgSO}_{4} 1.2, \mathrm{NaH}_{2} \mathrm{PO}_{4}$ 1.2, $\mathrm{NaHCO}_{3} 25.5$, Glucose 5.5. The distal portion of the muscular intrapulmonary arteries was dissected free from the surrounding lung parenchyma and cut into rings (2.5$3 \mathrm{~mm}$ length) taking care not to touch the luminal surface. Care was also taken to obtain the rings from the equivalent portion of artery at each age. The external diameter therefore ranged from $2 \mathrm{~mm}$ in the neonate to $3.5 \mathrm{~mm}$ in the adults. These were the arteries accompanying the bronchioles (fourth to fifth-generation intralobar pulmonary arteries). In some rings, the endothelium was removed by gently rubbing the luminal surface with watchmaker's forceps. A total of 6-10 rings were taken from each animal.

\section{Pharmacological protocols}

Each ring was suspended in a 13-mL organ bath filled with Krebs solution at $37^{\circ} \mathrm{C}$, gassed with $95 \%$ O2 and 5\% $\mathrm{CO}_{2}$ and attached to a transducer (Amplifier 6112; Palmer Bioscience, Cambridge, UK). Isometric forces were recorded on a polygraph (Linseis-L6514; Prolabo, Fontenaysous-Bois, France). Each ring was stretched progressively and exposed to two conditioning doses of $\mathrm{KCl}(40 \mathrm{mM})$. The rings were incubated with indomethacin $\left(10^{-5} \mathrm{M}\right)$ to inhibit prostanoids production and allowed to equilibrate for $60 \mathrm{~min}$.

To compare the influence of the endothelium on the smooth muscle response to relaxant substances, rings with and without endothelium were precontracted with prostaglandin $\mathrm{F}(\mathrm{PGF})_{2 \alpha}\left(10^{-5} \mathrm{M}\right)$. When a steady level of tone was obtained, cumulative concentration response curves to either ACh or the KATP channel opener CMK $\left(10^{-9}-10^{-4}\right.$ $\mathrm{M})$ were obtained by adding the drug in log increments. This concentration of $\mathrm{PGF}_{2 \alpha}$ was chosen because previous experiments had shown that it produced reproducible, consistent contractions at all ages, and this concentration represents the median effective concentration $\left(\mathrm{EC}_{50}\right)$ [19]. In a parallel, simultaneous series of experiments the authors tested the effect of the NOS inhibitor $N^{\omega}$-nitro-Larginine (L-NA; $\left.10^{-4} \mathrm{M}\right)$, the KATP channel blocker, glibenclamide $\left(10^{-5} \mathrm{M}\right)$ and the inhibitor of the ET-A receptor, BQ123 $\left(10^{-5} \mathrm{M}\right)$, on the relaxant response to $\mathrm{ACh}$ and $\mathrm{CMK}$. The authors also looked at the relaxant response to the ET-B activator, SF6c $\left(10^{-12}-10^{-6} \mathrm{M}\right)$ at different ages. At the end of the experiment, all rings were exposed to sodium nitroprusside $\left(10^{-5} \mathrm{M}\right)$ to test the capacity of the smooth muscle to relax. Lastly, all of the rings were blotted on filter paper and weighed.

\section{Drugs}

The following drugs were used: $\mathrm{PGF}_{2 \alpha}, \mathrm{ACh}$, indomethacin, L-NA, sodium nitroprusside, CMK, SF6c (all from Sigma, Paris-La-Défense, France). Indomethacin and CMK were dissolved in ethanol (final concentration of ethanol $<0.01 \%$ ). Glibenclamide was obtained from Hoechst (Paris-La-Défense, France) and was also dissolved in ethanol. BQ123 was obtained from Neosystem (Strasbourg, France). All drug concentrations are expressed as the final molar concentration in the organ bath solution.

\section{Histology}

At the end of each experiment, the rings were fixed in glutaraldehyde, embedded in araldite, cut in thin $1 \mu \mathrm{m}$ sections and stained with toluidine blue to confirm the presence or absence of endothelium as appropriate.

\section{Data analysis}

For each animal 8-10 rings were studied, with and without endothelium, and $\mathrm{n}$ represented the number of rings tested. The relaxation was expressed as percentage of relaxation from the $\mathrm{PGF}_{2}$-induced tone. Results were expressed as median and range. The mean \pm SEM of each set of experimental data were only used to construct the doseresponse curves to various pharmacological substances. Statistical analysis was performed using the nonparametric Wilcoxon signed rank test to compare results obtained on rings with and without endothelium tested with (or without) various inhibitors, and rings from animals of different age groups. Values were considered statistically significant when $\mathrm{p}<0.05$.

\section{In situ hybridization}

Cryostat sections of $10 \mu \mathrm{m}$ were placed on ribonuclease (RNase)-free glass slides and hybridized with an ribonuclease (RNA) probe labelled with $\mathrm{P}^{33}$ to detect constitutive endothelial NOS mRNA. Sections were immediately fixed during $1 \mathrm{~h}$ at $4{ }^{\circ} \mathrm{C}$ in paraformaldehyde $4 \%$ dissolved in phosphate buffered saline (PBS) $0.1 \mathrm{M}$ (pH 7.4) and then washed twice during $5 \mathrm{~min}$ in PBS $0.1 \mathrm{M}$ at $4{ }^{\circ} \mathrm{C}$. Tissue sections were made permeable with proteinase $\mathrm{K}\left(1 \mu \mathrm{g} \cdot \mathrm{mL}^{-1}\right.$, tris $\mathrm{HCl} 100 \mathrm{mM}$, ethylene diamine tetraacetic acid (EDTA) diNa $50 \mathrm{mM}$ ) and washed with 
diethylpyrocarbonate (DEPC) 4\% and triehanolamine 0.1 $\mathrm{M}$ to reduce background noise. Tissue sections were then treated during $10 \mathrm{~min}$ with triethanolamine and acetic anhydride. After overnight incubation with the radiolabelled probe at $55^{\circ} \mathrm{C}$, unhybridized RNA probes were removed with RNase $\mathrm{A}$ and high-stringency washes with $2-0.5 \times$ saline sodium citrate $(\mathrm{SSC}=150 \mathrm{mM}$ sodium chloride and $15 \mathrm{mM}$ sodium citrate per litre, $\mathrm{pH} 7$ ) at 22$60^{\circ} \mathrm{C}$. The sections were then processed for autoradiography. Negative control experiments included adjacent lung sections hybridized with the sense probe.

The plasmid was kindly provided by P.A. Marsden (University of Toronto, Toronto, Ontario, Canada) [23], and RNA probe was synthesized with a Promega kit (Promega, Charbonnières, France).

\section{Immunohistochemical analysis}

Cryostat sections of tissue were immunostained with antiserum to human endothelial NOS produced by Transduction Laboratories (Paris, France). Monoclonal antibody to ET which binds specifically to ET-1, ET-2 and ET-3 is purchased from Affinity Bioreagents (Cambridge, UK).

\section{Results}

For each vessel studied, examination of the $1 \mu \mathrm{m}$ sections confirmed the presence or absence of endothelium, as appropriate. From 3 days of age the presence of endothelium was confirmed by the relaxant response to ACh at the end of the experiment. All rings from the same animals and from those of the same age responded in a similar manner, and therefore the data were pooled. All rings relaxed completely to sodium nitroprusside.

The inhibitory effects of L-NA and glibenclamide and the effect of BQ123, were tested on vasodilator responses to ACh and cromakalim. The contractile response to $10^{-5}$ $\mathrm{M}$ of $\mathrm{PGF}_{2 \alpha}$ was comparable at all ages and was expressed in gram of tension. There was no significant difference on the weight of the rings at all ages. The relaxant response

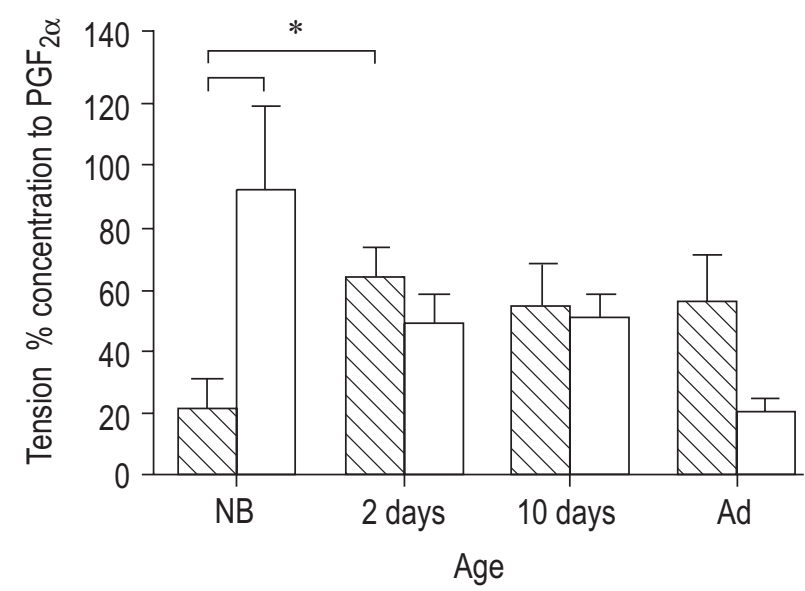

Fig. 1. - Relaxant response to cromakalim at different ages. Relaxant response as percentage relaxation from prostaglandin $\mathrm{F}(\mathrm{PGF})_{2 \alpha}$-induced tone in arteries with $(\mathbb{\nabla})$ and without $(\square)$ endothelium. NB: newborn $<2 \mathrm{~h}$ old; Ad: adult. *: $\mathrm{p}<0.05$. Data are presented as mean \pm SEM. was expressed as percentage relaxation of $\mathrm{PGF}_{2 \alpha}$-induced tone.

\section{In the newborn}

None of the arterial rings of newborn animals showed endothelium-dependent relaxation to $\mathrm{ACh}$ whereas some rings even showed a small contraction at high doses of ACh. Preincubation of the rings with the NOS inhibitor, LNA did not alter the response to $\mathrm{ACh}$, neither did glibenclamide, or BQ123. There was no difference in rings with or without endothelium.

In the newborn, all rings relaxed in response to CMK and the response was significantly less in rings with endothelium (median 26.5\%; range: 0-36\%) as compared with rings without endothelium (median 95\%; range: $55-$ $100 \%)(\mathrm{p}<0.05)$ (fig. 1). The relaxant response to $\mathrm{CMK}$ was unaffected by L-NA and was significantly reduced but not abolished by glibenclamide (fig. 2). In the presence of BQ123, the relaxant response to CMK improved significantly in rings with endothelium $(\mathrm{p}<0.01)$ thus the difference observed between rings with and without endothelium disappeared.
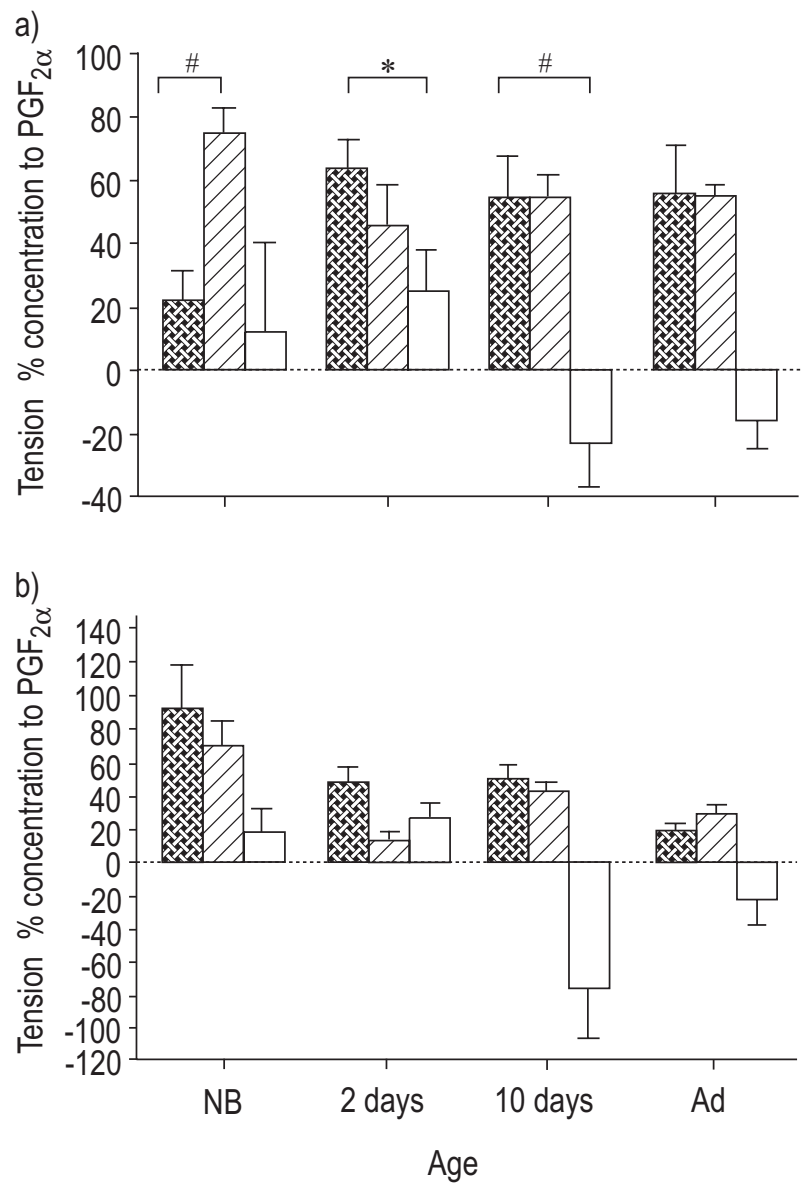

Fig. 2. - a) Relaxant response of endothelin-A receptor antagonist arteries with (瓷) endothelium to cromakalim (CMK) at different ages in the presence of endothelin-A antagonist, BQ123, $(\mathbb{Z})$ or the potassium channel blocker, glibenclamide $(\square)$. b) relaxant response as percentage relaxation from prostaglandin $\mathrm{F}(\mathrm{PGF})_{2 \alpha}$-induced tone in arteries with-

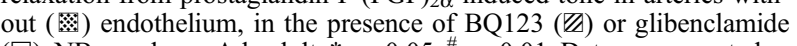
( $\square$ ). NB: newborn; Ad: adult. *: $p<0.05$; $^{*}: \mathrm{p}<0.01$. Data are presented as mean \pm SEM. 


\section{At 2-3 days}

Two animals out of five showed endothelium-dependent relaxation to ACh whereas the three others showed a small contraction at high dose of $\mathrm{ACh}$. In rings without endothelium, 3/4 showed a contraction in response to ACh.

In the presence of L-NA or glibenclamide (fig. 3), none of the rings with endothelium relaxed in response to ACh. However, preincubation with glibenclamide induced a contraction in response to $\mathrm{ACh}$ (median 60\%; range: 0 $100 \%$ ) which was significantly higher than in control rings with endothelium (median 3\%; range: $-43-20 \%$ ) $(\mathrm{p}<0.05)$. In the presence of BQ123, the response to ACh was not altered in rings with endothelium.

In the 2-3 day old animals, all rings with and without endothelium relaxed in response to CMK and the response increased in rings with endothelium as compared with newborn $(p<0.05)$ so that there was no difference between rings with and without endothelium at that age (fig. 1). The presence of L-NA did not alter the maximal response to CMK. Preincubation with glibenclamide reduced significantly but did not abolish the relaxant response to CMK $(p<0.05$ in rings with and without endothelium) (fig. 2).

In the presence of BQ123, the relaxant effect of CMK was unaffected in rings with endothelium, however, in rings without endothelium, relaxation to CMK appeared lower although the difference was not significant (fig. 2b).

\section{At 10 days of age}

The response to $\mathrm{ACh}$ in arteries with endothelium taken from the 10 day old animals $(n=4)$ was variable, the rings from two animals showing a similar relaxant response to that seen in the adult while the vessels from the other two showed only a small relaxant response. In the absence of endothelium, there was no relaxation but a small contraction in one animal.

Preincubation with L-NA reduced significantly the relaxant response to $\mathrm{ACh}(\mathrm{p}<0.05$; fig. 3).

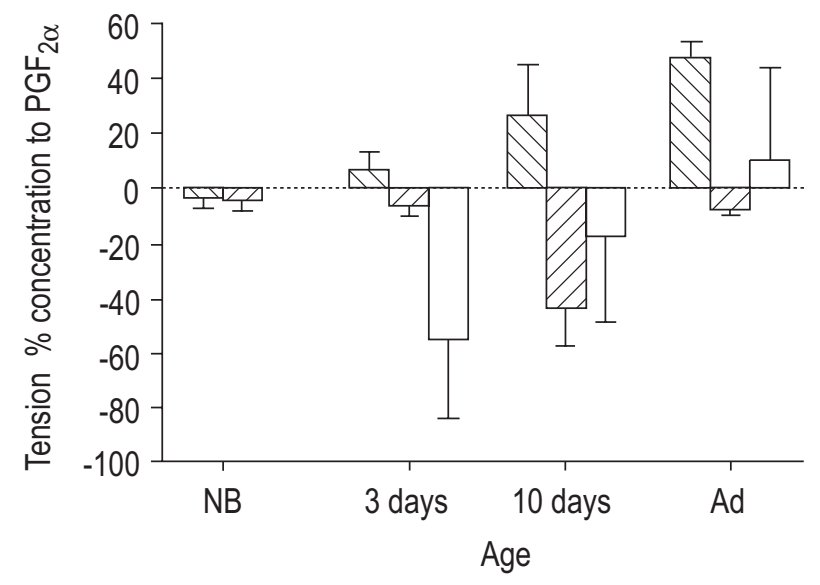

Fig. 3. - Response to acetylcholine (ACh) at different ages in arteries with endothelium $(\mathbb{\nabla})$ in the presence and the absence of the nitric oxide synthase inhibitor (L-NA) $(\mathbb{Z})$ and the potassium channel blocker, glibenclamide $(\square)$. Response as percentage relaxation from prostaglandin $\mathrm{F}(\mathrm{PGF})_{2 \alpha}$-induced tone, negative values for contractile response and positive for relaxant response to ACh. ${ }^{*}: \mathrm{p}<0.05$. Data are presented as mean \pm SEM.
In the presence of glibenclamide, the endotheliumdependent relaxation to $\mathrm{ACh}$ was reduced in four rings with endothelium out of five (fig. 3). There is no difference in rings without endothelium.

In the presence of BQ123, the response to $\mathrm{ACh}$ was similar to that observed in the control animals. At 10 days old, the maximal relaxation to CMK was similar to that observed at 2-3 days without a difference between the rings with or without endothelium. In the presence of $\mathrm{L}-$ $\mathrm{NA}$, the maximal relaxant response to CMK was similar to that observed in the control animals.

In the presence of glibenclamide, the relaxant response to CMK was totally abolished and two out of three rings with endothelium contracted whereas all rings without endothelium contracted $(\mathrm{p}<0.01$ for rings with and without endothelium; fig. 2).

In the presence of BQ123, the dose-response curve to CMK was slightly shifted to the left as compared with the control but this difference was not significant.

\section{In the adult animals}

There was an endothelium-dependent relaxation to ACh which was almost totally abolished by L-NA whereas glibenclamide reduced the endothelium-dependent response (fig. 3).

CMK induced a relaxant response in rings with and without endothelium which was unaffected by L-NA and BQ123 and abolished by glibenclamide (fig. 2).

\section{Response to sarafotoxin $6 c$}

In the newborn, endothelium-dependent relaxation to SF6c was observed in only one out of three animals at low dose and there was a contraction at high dose. With maturation, the endothelium-dependent relaxant effect of SF6c at low doses increased whereas the contractile effect observed at high doses decreased (fig. 4).

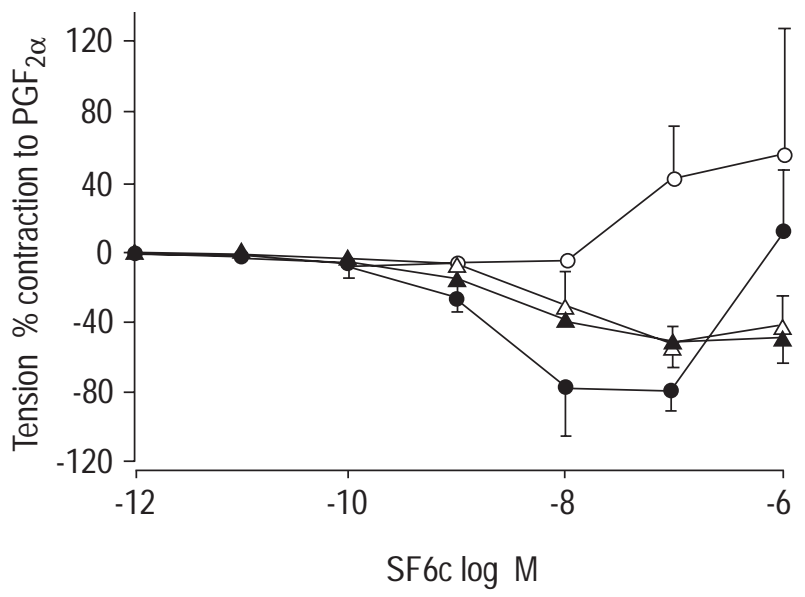

Fig. 4. - Dose response curve to the endothelin (ET)-B receptor agonist, sarafatoxin 6c (SF6c), at different ages. Relaxant response as percentage relaxation from prostaglandin $\mathrm{F}(\mathrm{PGF})_{2} \alpha$-induced tone in arteries with endothelium. $\bigcirc$ : newborn; $\bigcirc$ : 2 days; $\Delta: 10$ days; $\boldsymbol{\Lambda}$ : adult. Data are presented as mean \pm SEM. 

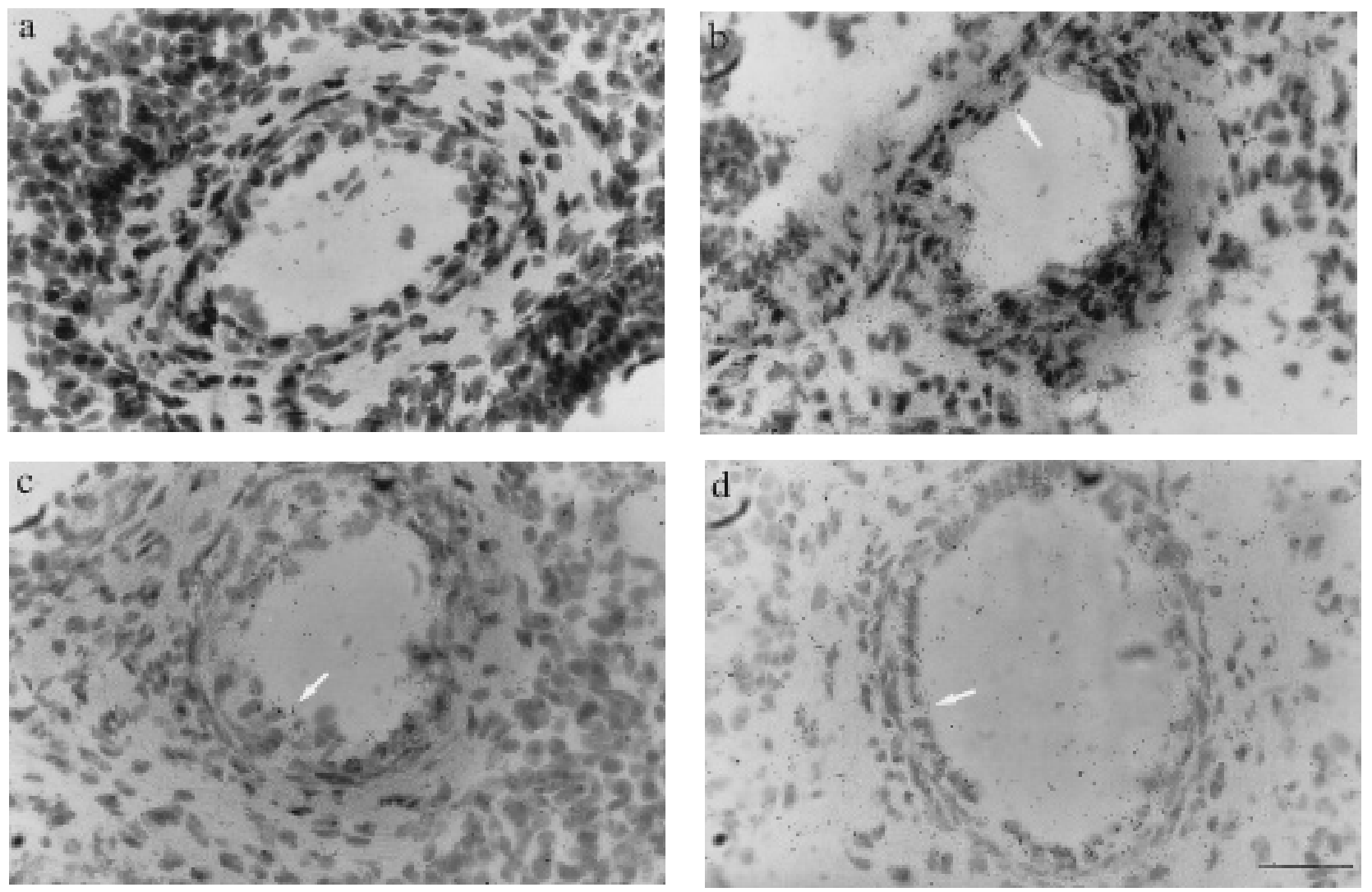

Fig. 5. - Expression of nitric oxide synthase (NOS)3 messenger ribonucleic acid (mRNA) in control (C) (a), newborn (b), 2 days (c), 10 days (d) old animals. Tissue sections were treated with triethanolamine and acetic anhydride, incubated overnight with the radiolabelled probe and processed for autoradiography. Internal scale bar $=500 \mu \mathrm{m}$. The white arrows indicate endothelial cell linings.

\section{Expression of nitric oxide synthase messenger ribo- nucleic acid}

The expression of NOS mRNA was present at all ages (fig. 5). However, it was lower in the newborn and increased with age.

\section{Expression of nitric oxide synthase protein}

The NOS protein was lower at birth in arteries and in the parenchyma than at 2-3 days and increased at 10 days (fig. 6 ). The protein was totally absent in the bronchus whereas the mRNA was expressed.

\section{Expression of endothelin}

There was a marked expression of ET in arteries and parenchyma in the newborn (fig. 7). This was decreased at 2 days and was increased again at 10 days but at a lower level than in the newborn.

\section{Discussion}

In this study, the authors have found that the endothelium-dependent relaxation to ACh is absent whereas the relaxant response to the KATP channel opener, CMK, is present at birth. The latter is, however, attenuated by the presence of endothelium. In adult porcine pulmonary artery, endothelium-dependent response to ACh is mediated by NO through activation of muscarinic M3 receptorsubtype [21]. In the immature porcine pulmonary artery, the response to ACh is mediated by both NO and EDHF. The latter being activated by muscarinic M1 receptorsubtype [20, 21]. CMK induces relaxation through activation of KATP channels. The resulting efflux of potassium ions causes hyperpolarization of the vascular smooth muscle cell membrane, hence vasorelaxation [24].

Reduced response to CMK indicates a vasoactive effect of the endothelial cells at birth. This is consistent with the observation that endothelium at birth increases constriction induced by vasoconstrictor substances such as $\mathrm{PGF}_{2 \alpha}$ and $\mathrm{KCl}$ [19]. The contractile effect of the endothelium is attributed to ET-1 and arachidonic acid metabolises [25]. The latter are unlikely to be involved in this study due to the presence of indomethacin.

It has been shown that plasma levels of ET-1 are greater at birth as compared with 3 days and 10 days after birth [19]. The physiological effect of ET-1 is complex, depending on the dose, the initial blood pressure and the type of vascular bed $[26,27]$. ET-1 induces pulmonary vasoconstriction by activation of both ET-A and ET-B receptors whereas it induces transient vasorelaxation exclusively by activation of ET-B receptors [28, 29]. Vasodilatation is partly due to a release of NO [30], prostacyclin [31] and EDHF [32]. The vasoactive effect of ET depends on the pulmonary vascular tone, as it can 

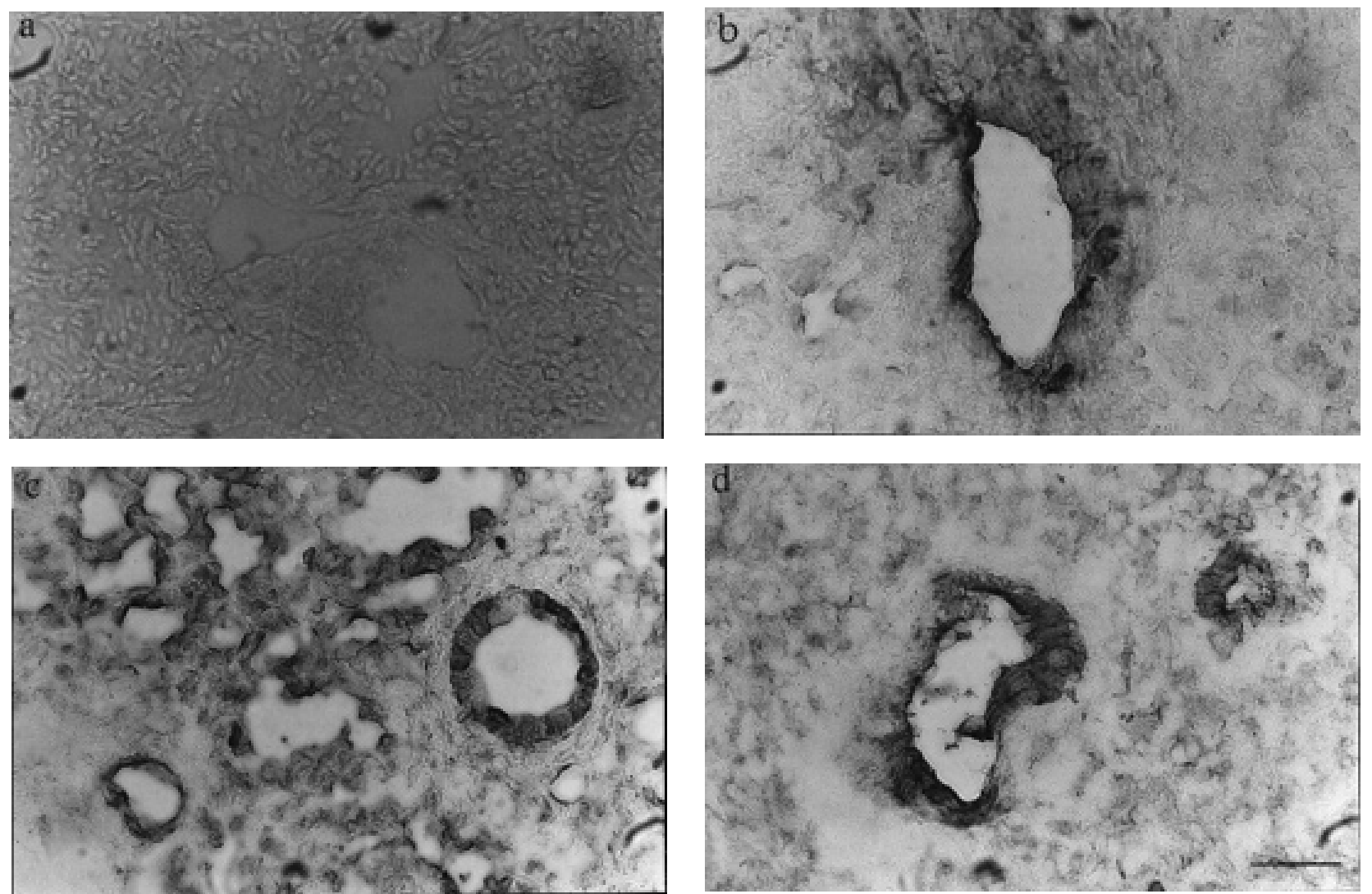

Fig. 6. - Expression of nitric oxide synthase (NOS) 3 protein in control (C) (a), newborn (b), 2 days (c), 10 days (d) old animals. Tissue sections were incubated with NOS3 antibodies. NOS3 antigen-antibody complexes were detected using the avidin biotin procedure and visualized by peroxidase substrate solution. Internal scale bar $=500 \mu \mathrm{m}$.

either dilate or constrict the vasculature in control and hypertensive lambs, respectively [33]. The vasoconstrictor effect of ET has been shown to be greater in the newborn period [34]. In newborn pulmonary arteries, there are mainly ET-A receptors whereas expression of ET-B is low at birth and increases at 2 days [35]. Hypoxia induces pulmonary hypertension, right heart hypertrophy and pulmonary vascular remodelling that can be totally reversed and prevented by the inhibitor of ET-A receptors [36].

At birth, the relaxant response to $\mathrm{CMK}$ is not affected by the NOS inhibitor, L-NA, whereas it is inhibited by glibenclamide. In order to know if the reduced response to $\mathrm{CMK}$ in rings with endothelium is due to release of a vasoconstrictor substance such as endothelin, the authors tested the effect of BQ123 which significantly increases the relaxant response to CMK to the level of rings without endothelium. Thus, there is possible interaction between EDHF and ET. There is evidence to suggest that EDHF acts mainly on KATP channel [24, 37], which can be blocked by glibenclamide [38, 39]. EDHF seems to be involved in the decrease of pulmonary resistance at birth $[20,40]$ and is more effective in hypertensive lung [41]. In the current study it appears that the endothelium reduces the relaxant effect of CMK at least partially by the activation of ET-A receptors.

Despite a predominant constrictor effect of the endothelium at birth, the release of endothelial-derived NO is also present at that age in ovine and porcine pulmonary arteries $[12,19,20,42]$. The NOS mRNA and the NOS protein are both present at birth but at a lower density than at 2 and 10 days of age. This study has found a higher expression of ET-1 at birth. Thus, it appears that in newborn porcine lung, the density of ET-1 receptors is higher than at 10 days whereas the converse is true with expression of NOS protein. This may explain how, at birth, the endothelium inhibits the relaxant response to CMK by the release of ET and that its customary relaxant effect appears between the second and third days of life. The constricting effect of the endothelium at birth can also be attributed to an increased production of superoxide anions due to a sudden increase of oxygen level [43, 44].

The lack of response to ACh at birth is not due to the activation of the ET-A receptors as BQ123 did not modify the response. Thus it is probably due to an immaturity of the muscarinic receptors.

Endothelium-dependent relaxant response to $\mathrm{ACh}$ is absent in all animals by 2 days of age and only appears between the second and the third day of life [20]. However, in rings with endothelium, ACh induced a contraction in the presence of the KATP channel blocker, glibenclamide indicating a release of EDHF in response to ACh at that age. In the presence of the NOS inhibitor, L-NA, ACh also induces a contraction which is much smaller than that observed with glibenclamide, indicating that EDHF can be more important than NO in the vasodilatory response to $\mathrm{ACh}$ at that age. The ET-A receptor antagonist, BQ123, did not modify the response 

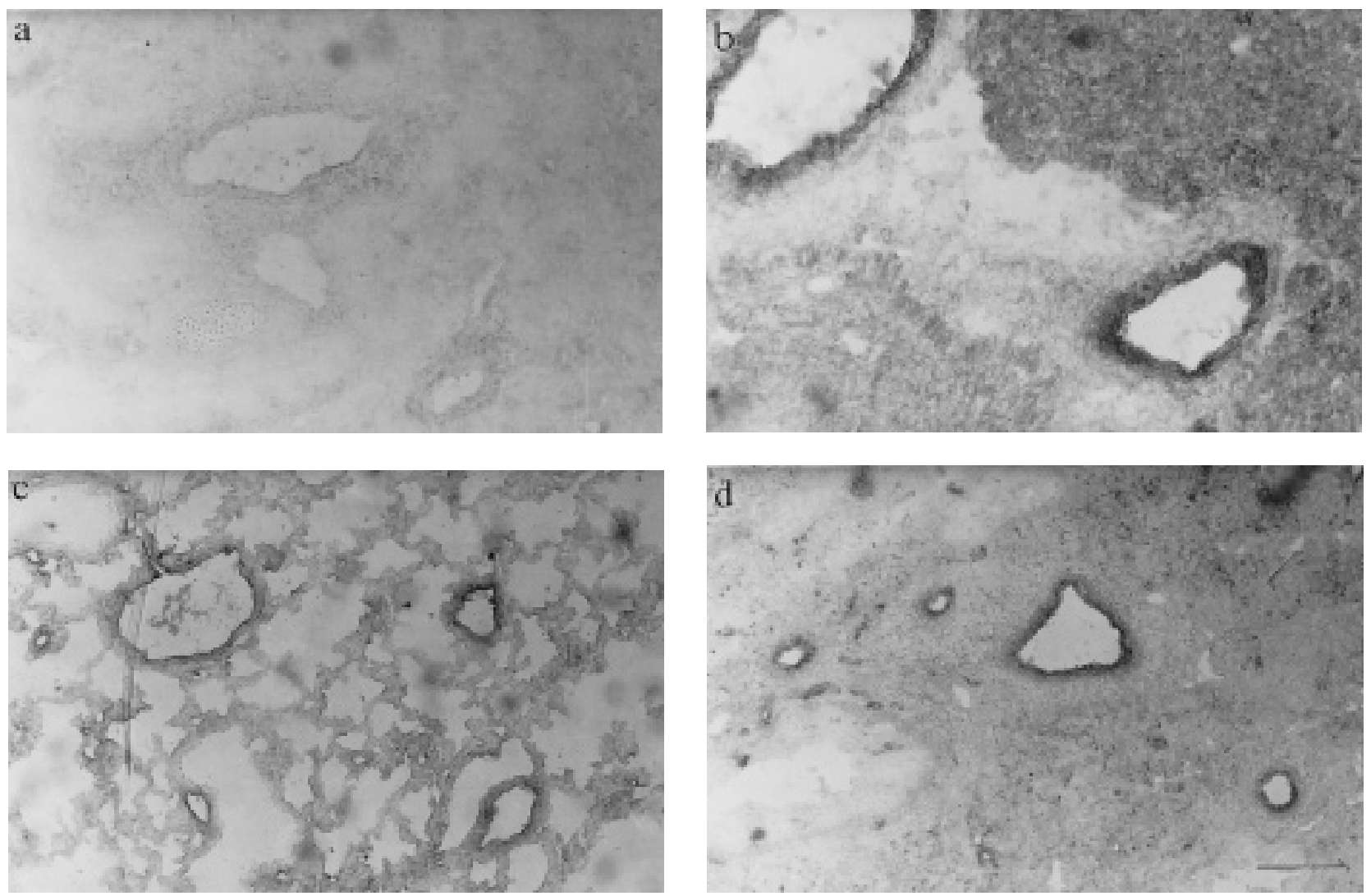

Fig. 7. - Expression of endothelin (ET)-1 protein in control (C) (a), newborn (b), 2 days (c), 10 days (d) old animals. Tissue sections were incubated with ET-1 antibodies. ET-1 antigen-antibody complexes were detected using the avidin biotin procedure and visualized by peroxidase substrate solution. Internal scale bar $=500 \mu \mathrm{m}$.

to ACh, indicating that the lack of relaxation to ACh during the first 3 days of life is not due to an excessive vasoconstriction to ET-1 but may be due to an immaturity of the mechanisms determining the release of $\mathrm{NO}$ as suggested by the lower density of NOS in the first days of life as well as an immaturity of the EDHF pathway.

At 10 days, the endothelium-dependent relaxation to $\mathrm{ACh}$ is variable but is unaffected by glibenclamide while it is inhibited by L-NA. These results suggest that between 210 days the response to $\mathrm{ACh}$ is mediated by different factors, mainly EDHF at 2 days and NO at 10 days [20].

This study demonstrates maturational changes in the modulatory role of the endothelium in response to acetylcholine and cromakalim and maturation-related changes in the expression of endothelin-1 and endothelial nitric oxide synthase. The newborn predisposition to excessive reactivity and vasoconstriction may be due to an important effect of endothelin-1 associated with an immaturity of the mechanisms determining endothelium-dependent relaxation. The important relaxant response to cromakalim in the presence of the endothelin-A receptor inhibitor, BQ123 at birth, and the endothelium-dependent relaxation to sarafotoxin $6 \mathrm{c}$ from 2 days of age are critical factors that might be useful in the treatment of pulmonary hypertension in the newborn.

\section{References}

1. Haworth SG, Hislop AA. Adaptation of the pulmonary circulation to extra-uterine life in the pig and its relevance to the human infant. Cardiovasc Res 1981; 15: $108-119$.

2. Hall S, Haworth SG. Conducting pulmonary arteries: structural adaptation to extra-uterine life. Cardiovasc Res 1986; 21: 208-216.

3. Allen K, Haworth SG. Human post-natal pulmonary arterial remodelling: ultrastructural studies of smooth muscle cell and connective tissue maturation. Lab Invest 1988; 59: 702-709.

4. Zellers TM, Vanhoutte PM. Endothelium-dependent relaxations of piglet pulmonary arteries augment with maturation. Pediatr Res 1991; 30: 176-180.

5. Perreault T, de Marte J. Maturational changes in endothelium-derived relaxations in newborn piglet pulmonary circulation. Am J Physiol 1993; 264: H302-H309.

6. Vanhoutte PM, Rubanyi GM, Miller VM, Houston DS. Modulation of vascular smooth muscle contraction by the endothelium. Annu Rev Physiol 1986; 48: 307-320.

7. Martin W, Furchgott RF, Villani GM, Jothianandan D. Depression of contractile responses in rat aorta by spontaneously released endothelium-derived relaxing factor. $J$ Pharmacol Exp Ther 1986; 237: 529-538.

8. Crawley DE, Liu SF, Evans TW, Barnes PJ. Inhibitor role of endothelium-derived relaxing factor in rat and human pulmonary arteries. Br J Pharmacol 1990; 101: 166-170.

Acknowledgements. The authors are indebted to P. Marsden for having provided the probe of the ecNOS3.
9. Abman SH, Chatfield BA, Hall SL, McMurtry IF. Role of endothelium-derived relaxing factor during transition of 
pulmonary circulation at birth. Am J Physiol 1990; 259: H1921-H1927.

10. Steinhorn RH, Morin FC III, Gugino SF, Giese EC, Russell JA. Developmental differences in endotheliumdependent responses in isolated ovine pulmonary arteries and veins. Am J Physiol 1993; 264: H2162-H2167.

11. Liu SF, Hislop AA, Haworth SG, Barnes PJ. Developmental changes in endothelium-dependent pulmonary vasodilation in pigs. Br J Pharmacol 1992; 106: 324-330.

12. Abman SH, Chatfield BA, Rodman DM, Hall SL, McMurtry IF. Maturational changes in endotheliumderived relaxing factor activity of ovine pulmonary arteries in vitro. Am J Physiol 1991; 260: L280-L285.

13. Fineman JR, Heymann MA, Soifer SJ. $N^{\omega}$-nitro-Larginine attenuates endothelium-dependent pulmonary vasodilation in lambs. Am J Physiol 1991; 260: H1299H1306.

14. Davidson D. Pulmonary hemodynamics at birth: effect of acute cyclooxygenase inhibition in lambs. J Appl Physiol 1988; 64: 1676-1682.

15. Altura BM, Chand N. Bradykinin-induced relaxation of renal and pulmonary arteries is dependent upon intact endothelial cells. Br J Pharmacol 1981; 74: 10-11.

16. Chen GH, Suzuki H, Weston AH. Acetylcholine releases endothelium-derived hyperpolarizing factor and EDRF from rat blood vessels. Br J Pharmacol 1988; 95: 11651174.

17. Yanagisawa M, Kurihara H, Kumara S, et al. A novel potent vasoconstrictor peptide produced by vascular endothelial cells. Nature 1988; 332: 411-415.

18. Hamberg M, Svensson J, Samuelsson B. Thromboxanes: a new group of biologically active compounds derived from prostaglandin endoperoxides. Proc Natl Acad Sci USA 1975; 72: 2994-2998.

19. Lévy M, Tulloh RMR, Komai H, Stuart-Smith K, Haworth SG. Maturation of the contrachle response and its endothelial modulation in newborn porcine intrapulmonary arteries. Pediatr Res 1995; 38: 25-29.

20. Lévy M, Stuart-Smith K, Haworth SG. Newborn porcine intrapulmonary arterial relaxation muscarinic receptor subtype and cyclic GMP levels. Am Rev Respir Dis 1993; 147: A417.

21. Rubanyi GM, McKinney M, Vanhoutte PM. Biphasic release of endothelium-derived relaxing factor(s) by acetylcholine from perfused canine femoral arteries: characterisation of muscarinic receptors. J Pharmacol Exp Ther 1987; 240: 802-808.

22. Bayne K. Developing guidelines on the care and use of animals. Am N Y Acad Sci 1998; 862: 105-110.

23. Marsden PA, Schapport KT, Chen HS, et al. Molecular cloning and characterization of human endothelial nitric oxide synthase. FEBS Lett 1992; 307: 287-293.

24. Standen NB, Quayle JM, Davies NW, Brayden JE, Huang Y, Nelson MT. Hyperpolarizing vasodilators activate ATP-sensitive $\mathrm{K}+$ channels in arterial smooth muscle. Science 1989; 245: 177-180.

25. Miller VM, Vanhoutte PM. Endothelium-dependent contractions to arachidonic acid are mediated by products of cyclooxygenase. Am J Physiol 1985; 248: H432-H437.

26. De Nucci G, Thomas R, D'orleans-Juste P, et al. Pressor effects of circulating endothelin are limited by its removal in the pulmonary circulation and by the release of prostacyclin and endothelium-derived relaxing factor. Proc Natl Acad Sci USA 1988; 85: 9797-9800.

27. Lippton HL, Ohlstein EH, Summer WR, Hyman AL. Analysis of responses to endothelins in the rabbit pul- monary and systemic vascular beds. J Appl Physiol 1991; 70: 331-341.

28. Sato K, Oka M, Hasunuma K, Ohnishi M, Sato K, Kira S. Effects of separate and combined ETA and ETB blockade on ET-1 induced constriction in perfused rat lungs. Am J Physiol 1995; 269: L668-L672.

29. MacLean MR, McCulloch KM, Baird M. Endothelin ETA- and ETB- receptor-mediated vasoconstriction in rat pulmonary arteries and arterioles. $J$ Cardiovasc Pharmacol 1994; 23: 838-845.

30. Sabry S, Mondon F, Lévy M, Ferré F, Dinh-Xuan AT. Endothelial modulation of vasoconstrictor responses to endothelin-1 in human placental stem villi small arteries. Br J Pharmacol 1995; 115: 1038-1042.

31. Zellers TM, McCormick J, Wu Y. Interaction among ET1 , endothelium-derived nitric oxide, and prostacyclin in pulmonary arteries and veins. Am J Physiol 1994; 267: H139-H147.

32. Lippton HL, Cohen GA, McMurtry IF, Hyman A. Pulmonary vasodilation to endothelin isopeptide in vivo is mediated by potassium channel activation. $J$ Appl Physiol 1991; 70: 947-952.

33. Wong J, Reddy VM, Hendricks-Munoz K, Liddicoat JR, Gerrets R, Fineman JR. Endothelin-1 vasoactive responses in lambs with pulmonary hypertension and increased pulmonary blood flow. Am J Physiol 1995; 269: H1965-H1972.

34. Liben S, Stewart DJ, de Marte J, Perreault T. Ontogeny of big endothelin-1 effects in newborn piglet pulmonary vasculature. Am J Physiol 1993; 265: H139-H145.

35. Hislop AA, Zhao YD, Springall DR, Polak JM, Haworth SG. Postnatal changes in endothelin-1 binding in porcine pulmonary vessels and airways. Am J Respir Cell Mol Biol 1995; 12: 557-562.

36. DiCarlo VS, Chen SJ, Meng QC, et al. ET-A-receptor antagonist prevents and reverses chronic hypoxia-induced pulmonary hypertension in rat. Am J Physiol 1995; 269: L690-L697.

37. Suzuki H, Chen G. Endothelium-derived hyperpolarizing factor (EDHF): an endogenous potassium channel activator. News Physiol Sci 1990; 5: 212-215.

38. Quast U, Cook NS. Moving together: $\mathrm{K}+$ channel openers and ATP-sensitive $\mathrm{K}+$ channels. Trends Pharmacol Sci 1989; 10: 431-435.

39. Clapp LH, Davey R, Gurney AM. ATP-sensitive K+ channels mediate vasodilation produced by lemakalim in rabbit pulmonary artery. Am J Physiol 1993; 264: H1907H1915.

40. Cornfield DN, McQueston JA, McMurtry IF, Rodman DM, Abman SH. Role of ATP-sensitive potassium channels in ovine fetal pulmonary vascular tone. Am J Physiol 1992; 263: H1363-H1368.

41. Pinheiro JMB, Malik AB. K+ ATP-channel activation causes marked vasodilation in the hypertensive neonatal pig lung. Am J Physiol 1992; 263: H1532-H1536.

42. Shaul PW, Wells LB. Oxygen modulates nitric oxide production selectively in fetal pulmonary endothelial cells. Am J Respir Cell Mol Biol 1994; 11: 432-438.

43. Rubanyi GM, Vanhoutte PM. Superoxide anions and hyperoxia inactivate endothelium-derived relaxing factor. Am J Physiol 1986; 250: H822-H827.

44. Cassin S, Kristova V, Davis T, Kadowitz P, Gause G. Tone-dependent responses to endothelin in the isolated perfused fetal sheep pulmonary circulation in situ. J Appl Physiol 1991; 70: 1228-1234. 